\title{
Face recognition and emotional valence: Processing without awareness by neurologically intact participants does not simulate covert recognition in prosopagnosia
}

\author{
ANNA STONE, TIM VALENTINE, and ROB DAVIS \\ Goldsmiths College, University of London, London, England
}

\begin{abstract}
Covert face recognition in neurologically intact participants was investigated with the use of very brief stimulus presentation to prevent awareness of the stimulus. In Experiment 1, skin conductance response (SCR) to photographs of celebrity and unfamiliar faces was recorded; the faces were displayed for $220 \mathrm{msec}$ and for $17 \mathrm{msec}$ in a within-participants design. SCR to faces presented for 220 msec was larger and more likely to occur with familiar faces than with unfamiliar faces. Face familiarity did not affect the SCR to faces presented for $17 \mathrm{msec}$. SCR was larger for faces of good than for faces of evil celebrities presented for $17 \mathrm{msec}$, but valence did not affect SCR to faces displayed for $220 \mathrm{msec}$. In Experiment 2, associative priming was found in a face familiarity decision task when the prime face was displayed for $220 \mathrm{msec}$, but no facilitation occurred when primes were presented for 17 msec. In Experiment 3, participants were able to differentiate evil and good faces presented without awareness in a two-alternative forced-choice decision. The results provide no evidence of familiarity detection outside awareness in normal participants and suggest that, contrary to previous research, very brief presentation to neurologically intact participants is not a useful model for the types of covert recognition found in prosopagnosia. However, a response based on affective valence appears to be available from brief presentation.
\end{abstract}

Prosopagnosia is a neuropsychological condition in which patients cannot consciously identify familiar people from their faces but remain able to identify them from their names or voices. The condition is due neither to memory loss nor to visual impairment but to the dissociation of the percept of a face from stored memory representations (Young, 1998). Prosopagnosic patients show impaired performance in direct tests of face recognition. For example, they cannot name familiar faces or make a forced choice between a familiar and an unfamiliar face. However there is a substantial body of evidence that some patients can demonstrate face recognition in indirect tests. Prosopagnosic patients can show a higher skin conductance response to familiar faces than to unfamiliar faces (see, e.g., Tranel \& Damasio, 1985; Tranel, Damasio, \& Damasio, 1995) and a higher skin conductance response to correct face-name pairs of celebrities than to incorrect pairings (e.g., Bauer, 1984, 1986; Bauer \& Verfaellie, 1988). Behavioral measures have demonstrated that some identityspecific semantic information about celebrities can be activated in some prosopagnosic patients. For example, a

This work was supported by the Nuffield Foundation, reference NUF URB99. Correspondence should be addressed to A. Stone, Department of Psychology, Goldsmiths College, New Cross, London SE14 6NW, England (e-mail: psp01ams@gold.ac.uk). celebrity's face that is not overtly recognized can facilitate recognition of a subsequently presented name of the same person (De Haan, Bauer, \& Greve, 1992) or a closely associated individual (Young, Hellawell, \& De Haan, 1988).

Two main explanations have been offered for the phenomenon of covert face recognition in prosopagnosia. Burton, Young, Bruce, Johnston, and Ellis (1991) have proposed that covert recognition in prosopagnosia can be simulated by a reduction in the connection strength between units that represent familiar faces and units that represent the identity of known individuals in an interactive activation and competition network. By this account, the behavioral effects of covert recognition are the result of the subthreshold activation of semantic information relating to a specific individual. The activation is insufficient to enable an overt familiarity decision to be made, but it is sufficient to facilitate subsequent recognition of the names of related celebrities, which is unimpaired. The Burton et al. model does not address the finding of skin conductance response (SCR) discrimination between familiar and unfamiliar faces.

Breen, Caine, and Coltheart (2000) have proposed that face recognition is mediated by two functionally and anatomically separate neural routes. The "semantic" route, which is equivalent to the Burton et al. (1991) model, mediates overt recognition, and the "affective" route mediates emotional arousal and hence the SCR to familiar 
faces. Damage to the "semantic" route results in prosopagnosia while the behavioral effects of covert recognition are mediated by residual functioning of this route. Alternative dual-route models have been proposed by Tranel et al. (1995) and Bauer (1984, 1986). Dual-route models are consistent with the view that affect and cognition are mediated by separate and partially independent systems, in which affective responses can occur in the absence of conscious recognition of a stimulus ( $\mathrm{Za}-$ jonc, 1980). They are also consistent with Ellis and Young's (1990) suggestion that prosopagnosia and Capgras syndrome form a double dissociation, with overt recognition impaired in prosopagnosia and affective response impaired in Capgras syndrome. See Ellis, Young, Quayle, and De Pauw (1997) for empirical support for this view.

Meeres and Graves (1990) employed the method of using brief exposure durations with neurologically intact participants in order to simulate effects of preconscious perception in neuropsychological patients. They found effects analogous to the phenomenon of "blindsight," whereby participants could define the location of stimuli presented too briefly for conscious perception. Similarly, Ellis, Young, and Koenken (1993) claim to have demonstrated SCR discrimination of familiar and unfamiliar faces without overt recognition in neurologically intact participants. However, their method of determining the exposure duration relied on each participant's ability to name, or provide unique biographical information about, celebrity faces as an index of overt recognition. This method may have been too insensitive. The authors acknowledge that some participants did achieve recognition of some faces. They quote an example exposure duration of $50 \mathrm{msec}$, whereas pilot work in our laboratory showed that participants were able to identify some faces from a masked presentation of $33 \mathrm{msec}$ and recognition was good with a masked presentation of $50 \mathrm{msec}$. Similarly, Mogg and Bradley (1999) found some overt recognition of facial expressions for a masked 33-msec exposure duration. Ellis et al. (1993) did not question participants after the experiment to determine whether any faces had been recognized. The thresholds were not measured again after the skin conductance recording task to investigate whether participants might have an increased ability to detect masked faces as a result of practice.

Morrison, Bruce, and Burton (2000) claim to have demonstrated that a prime face presented too briefly for conscious recognition facilitates a familiarity decision to the face of a closely associated individual. However, they report using mean exposure durations intended to prevent overt recognition of $65-72 \mathrm{msec}$ in three experiments and their methods are open to the same criticisms as those applied above to Ellis et al. (1993). It appears that in both Ellis et al. (1993) and Morrison et al. (2000), the participants were likely to have been aware of at least some of the primes presented at the quoted durations. So discriminative responding based on facial familiarity or seman- tic associations has yet to have been clearly established in nonimpaired participants.

There is, however, evidence that facial expressions of emotion presented without conscious awareness can result in differential SCR (see Ohman, Esteves, \& Soares, 1995, for a review) or orienting of attention (Mogg \& Bradley, 1999). So it appears that differential responding can be obtained on the basis of the positive or negative affective valence of a stimulus of which the participant is unaware.

Breen et al. (2000) ascribed the larger SCR for familiar than for unfamiliar faces in prosopagnosics to greater affective arousal. So the SCR to familiar faces may be stronger with faces of greater affective significance regardless of valence. Some support for this hypothesis comes from previous related studies. Maltzman and Boyd (1984) showed that visual images rated as either strongly pleasant or strongly unpleasant resulted in larger SCRs than did neutral images. Ohman and Soares (1994) found that spider- or snake-fearful participants gave larger SCRs to feared stimuli than to neutral flowers or mushrooms.

In the experiments reported here, we had the following aims: first, to establish whether neurologically intact participants would show a difference in SCR between familiar and unfamiliar faces when the stimuli were presented at a duration that unambiguously prevented awareness; second, to establish whether SCR to famous faces would prove to be related to their affective significance, or to their affective valence, for both aware and unaware processing; and third, to establish whether a prime face of which a participant was unaware could facilitate subsequent overt recognition of a related face. The effects on SCR were tested in Experiment 1, and associative priming was investigated in Experiment 2.

The duration of $17 \mathrm{msec}$ was selected to ensure that it would be unambiguous that participants were unaware of the prime faces, but to also ensure that the prime faces would still be perceptible. Mogg and Bradley (1999) have found evidence of the unconscious recognition of facial expressions at a duration of $14 \mathrm{msec}$, suggesting that faces are perceptible at a duration of $17 \mathrm{msec}$.

Pilot data suggested that virtually no faces could be consciously identified at an exposure duration of $17 \mathrm{msec}$, but that some conscious recognition was possible at $33 \mathrm{msec}$ and substantial recognition occurred at $50 \mathrm{msec}$. The faces used in the pilot study were the same 18 famous faces and 12 unfamiliar faces that were used in the experiment, and they were displayed with the same forward and backward masks. Presentation of each face was initiated by the participant's pressing a key, and unlimited time was allowed following presentation for the participant to attempt to identify the face. The participants were strongly encouraged to guess the identity of each face. At $17 \mathrm{msec}$, of the 8 participants tested, only 1 participant correctly identified only 1 face. At $33 \mathrm{msec}$, another 8 participants were tested; this resulted in a total of 14 correct identifications, giving a mean number of correct identifications of 1.75 
(10\%) per participant. At $50 \mathrm{msec}$, of the 2 participants tested, 1 identified 13 faces and 1 identified 6 faces, giving a mean of $9.5(53 \%)$ faces per participant.

\section{EXPERIMENT 1}

\section{Method}

Participants. Forty-two students and staff of the Goldsmiths College Psychology Department took part. The participants included 9 men and 33 women with ages ranging from 18 to 48 (mean age $=$ 22.1 years, $S D=6.2$ ). All participants were required to have been resident in the U.K. for a minimum of 18 years, in order to ensure the prospect of recognition of the famous faces. None of the participants had taken part in the preexperimental rating task.

Stimuli. Photographs of familiar and unfamiliar faces of a uniform quality were digitized to produce images of 16 grays, $256 \times$ 256 pixels in size. The faces were rated for distinctiveness, familiarity, age of acquisition, and affective valence by 16 participants (3 male and 13 female, mean age 29.5 years, $S D=13.7$ ). The ratings were collected in two phases: First the famous faces were rated for familiarity, age of acquisition, and affective valence, and then all faces were rated for distinctiveness. Ratings of famous faces were recorded only when the participant gave an accurate identif ication, either by naming or by providing unique biographical information. The faces were presented in a different random sequence to each participant. The participants were instructed that there were no right answers, that their personal opinion was the important factor, and that they should proceed at their own speed. Familiarity was rated on a 7-point scale $(1=$ unknown, $7=$ extremely familiar $)$ to reflect the number of times that the face had been previously encountered in any form, whether on TV, in a film, newspaper, or magazine, and so forth. Approximate age of acquisition was assessed on a 7-point scale (never seen before, under 3 years old, under 6, under 9, under 12, under 18, over 18) to reflect the age at which the face had first been seen. It is recognized that age of acquisition can only be estimated by the participant. Nevertheless recent studies have shown that speed and accuracy of face processing is affected by age of acquisition (Moore \& Valentine, 1998; Moore, Valentine, \& Turner, 1999). Therefore it was necessary that this attribute be matched across stimulus sets. Affective valence was assessed on a 7-point scale $(-3=$ evil/threatening, $0=$ neutral,$+3=$ good/inviting $)$ considering the participant's knowledge of the celebrity. Distinctiveness was rated on a 7 -point scale $(1=$ very typical, $7=$ very distinctive). The participants were asked to imagine that they had never seen the person before and had been given this photograph and asked to meet the person at a busy station, and to rate how easy it would be to spot them in the crowd. The ratings scales and questions for familiarity, age of acquisition, and distinctiveness were derived from Moore and Valentine.

Six evil, six neutral, and six good famous faces (listed in Appendix A) and two sets of six unfamiliar faces were selected so that the sets were matched on sex, race, approximate age in the photograph, facial expression (categorized simply as neutral, smiling, or frowning), and distinctiveness (means: evil $=4.93$, neutral $=4.74$, good $=4.88$, unfamiliar $=4.76$ and 4.74 ). The three sets of famous faces were matched on rated familiarity (means: evil $=6.01$, neutral $=6.15$, good $=6.11$ ), age of acquisition (means: evil $=5.79$, neutral $=5.84$, good $=5.54$ ) and contrasted in affective valence (means: evil $=-1.79$, neutral $=0.95$, good $=2.07$ ). There were no signif icant differences among the three sets of familiar faces on familiarity or age of acquisition, or among the five sets of familiar and unfamiliar faces on distinctiveness (all $F \mathrm{~s}<1$ ). There were significant differences among the valence ratings of the famous faces $[F(2,15)=63.7, p<.001]$. Independent samples $t$ tests revealed that evil and neutral faces differed significantly $[t(5.5$; degrees of freedom adjusted for unequal variances $)=6.88, p<.001]$, and that neutral and good faces differed significantly $[t(10)=6.03, p<.001]$.

Materials. A personal computer running MEL2 software was used to display the faces at a $640 \times 480$ screen resolution. Skin conductance levels were measured with the use of standard commercially available circular $\mathrm{Ag} / \mathrm{AgCl}$ electrodes, $1 \mathrm{~cm}$ in diameter and coated with a bio-adhesive gel, supplied by SLE Diagnostics. The electrodes were affixed to the thenar and hypothenar eminences of the participant's least preferred hand, as recommended by Martin and Venables (1980). Custom-built equipment using a constant voltage system sampled skin conductance level at a frequency of $100 \mathrm{~Hz}$, and the data were transferred to a separate personal computer.

Design. The experiment used a within-participants design, with two independent factors: exposure duration (17 vs. $220 \mathrm{msec}$ ) and face type (evil, neutral, good, and unfamiliar). Two dependent variables derived from the SCR were calculated: the proportion of stimuli for which a response occurred and the maximum amplitude of the response.

Procedure. Immediately on arrival, each participant was asked to wash his/her hands in soap and water in order to standardize conditions as far as possible, as recommended by Martin and Venables (1980). The participants were tested individually in a darkened, airconditioned room.

Half the participants viewed faces first at $17 \mathrm{msec}$ and then at $220 \mathrm{msec}$; for the remainder of the participants, the order of exposure duration was reversed. A different set of unfamiliar faces was used for each exposure duration in order to ensure continued unfamiliarity. The two sets of unfamiliar faces were counterbalanced across order of presentation and across the two exposure durations. No indication was given about whether the same or different faces would be displayed in the two lists.

In the 17-msec condition, the participants were informed that a series of familiar and unfamiliar faces would be displayed on the screen for $17 \mathrm{msec}$ each. They were told that each face would be preceded and immediately followed by a mask created from an assortment of facial features and that there would be a 12 -sec interval between faces. The participants were asked to concentrate on the screen and attempt to perceive the faces but were informed that the exposure duration was set deliberately to make this very difficult. The participants were seated comfortably at a distance of approximately $2 \mathrm{ft}$ from the screen, and the electrodes were fixed on their hands. They were asked to remain perfectly still for the duration of exposure to the stimuli $(6 \mathrm{~min})$ with their hands resting in a relaxed position. No active response from the participants was required.

Two buffer faces, 1 familiar and 1 unfamiliar, were presented first, followed by the 18 familiar and 6 unfamiliar faces mixed in a different random sequence for each participant. The faces were displayed centrally on the monitor, filling an area of $2.5 \mathrm{in}$. square. Skin conductance level was recorded throughout the presentation of the faces.

After the skin conductance recording was complete, the electrodes were removed, and the participants were asked whether they had been able to recognize any of the faces. They were informed that it was extremely unlikely that any confident identifications could be made and that any recognition of any of the faces would be at the level of a vague intuition, and they were strongly encouraged to guess. The participants were asked whether they had experienced any names, or any other thoughts, popping into their mind. Finally, each participant was asked to produce the first three famous names that came into mind. In response to the last question, 5 participants revealed names of faces used in the experiment that they had not previously articulated. By contrast, 35 undergraduates who had not participated in the experiment and who were asked to produce the first three famous names that came to mind produced just two instances of faces used in the experiment.

In the 220-msec condition, the procedure was the same with the following exceptions: The faces were displayed for $220 \mathrm{msec}$; the 
participants were informed that the exposure duration was sufficient to permit recognition of familiar faces; and no questions were asked to ascertain whether any faces had been recognized.

All participants were asked to identify the familiar faces and provide ratings on familiarity, age of acquisition, and valence, and then to provide distinctiveness ratings for all faces used in the experiment, following the rating scales and procedures used in the preexperimental selection of stimuli.

\section{Results and Discussion}

Data from 5 participants were omitted from the analysis. Four participants failed to show any valid responses to either 220 or $17 \mathrm{msec}$ presentations or both, and 1 participant had previous experience with some of the unfamiliar faces used in the experiment. Data from the remaining 37 participants were analyzed.

The mean familiarity, age of acquisition, valence, and distinctiveness ratings provided by the experimental participants for each face were calculated. There were no significant differences among the three sets of familiar faces on familiarity or age of acquisition or among the five sets of familiar and unfamiliar faces on distinctiveness (all $F_{\mathrm{s}}<$ $1)$. There was significant difference among the valence ratings of the famous faces $[F(2,15)=51.5, p<.001]$. Independent samples $t$ tests revealed that evil and neutral faces differed significantly $[t(6.24$; degrees of freedom adjusted for unequal variances $)=5.81, p<.001]$, and that neutral and good faces differed significantly $[t(10)=5.74$, $p<.001]$. Faces were counted as familiar when the participant was able to provide an adequate identification, whether by naming or by providing unique biographical information.

The skin conductance data were analyzed by an algorithm to derive the dependent variables. The criterion for a valid response was that there should be a clear increase in the skin conductance level following presentation of a face and that this increase should peak within a defined window. A valid response was scored when the maximum skin conductance level recorded within a window of 1-10 sec after face onset was higher than the minimum skin conductance level recorded between face onset and the occurrence of the maximum. It was required that the maximum and minimum must be separated by at least $0.5 \mathrm{sec}$ and not more than $9.5 \mathrm{sec}$. Thus a valid response could not be scored if the minimum occurred at $0 \mathrm{sec}$ and the maximum at $10 \mathrm{sec}$ after face onset. In this case, the skin conductance level was steadily rising throughout the window, suggesting that some event other than the face stimulus was responsible for the skin conductance reaction. A response was deemed invalid if the baseline skin conductance level immediately preceding the response was lower than 3 microsiemens. At this baseline skin conductance, responses to displayed faces cannot be reliably distinguished from random variation, and so the criterion of a clear increase in the skin conductance level following presentation of a face, peaking within a defined window, is not met. A response to a familiar face was deemed invalid if the face was not subsequently identified in a familiarity check for the stimuli. A response to a $17-\mathrm{msec}$ presentation was also deemed invalid if the face was subsequently identified from this presentation, since in these cases the brief presentation had not prevented awareness of the stimulus.

Range-adjusted response amplitude (Rara) was calculated as response amplitude divided by largest response for the participant. Probability of response (Prob) was defined as the number of faces producing a valid response divided by the number of faces that could, potentially, have produced a valid response (i.e., familiar faces were not recognized from 17-msec presentation and were subsequently correctly identified). Prob was zero when a participant had no responses for a particular face type and exposure duration. However, no meaningful Rara could be recorded in such cases, so Rara was calculated only for the 20 participants with a minimum of two valid responses for both familiar and unfamiliar faces at the 17msec and 220-msec exposure durations. The means and standard deviations are shown in Table 1.

For the items analysis, each variable was calculated across the same participants who contributed to the participants analysis.

The comparison of familiar and unfamiliar faces gave no evidence of covert face recognition. The variables Rara and Prob were analyzed separately in two-factor analyses of variance (ANOVAs) with exposure duration as a within-participants and within-items factor and face type as a within-participants and between-items factor. The main effect of exposure duration was significant for $\operatorname{Rara}\left[F_{\mathrm{p}}(1,19)=4.90, p<.05 ; F_{\mathrm{i}}(1,22)=8.02, p<.01\right]$ and for Prob in the items analysis $\left[F_{\mathrm{p}}(1,36)=2.42\right.$, n.s.; $\left.F_{\mathrm{i}}(1,22)=4.90, p<.05\right]$, indicating that responses tended to be larger and more probable at $220 \mathrm{msec}$ than at $17 \mathrm{msec}$. The main effect of familiarity was also significant for Rara in the items analysis $\left[F_{\mathrm{p}}(1,19)=0.98\right.$, n.s.; $\left.F_{\mathrm{i}}(1,22)=4.66, p<.05\right]$ and for Prob in the participants analysis $\left[F_{\mathrm{p}}(1,36)=5.25, p<.05 ; F_{\mathrm{i}}(1,22)=2.97\right.$, n.s.], reflecting the trend for responses to familiar faces to be larger and more probable than those to unfamiliar

Table 1

Mean Probability of Response and Range-Adjusted Response Amplitude (Microsiemens) for Skin Conductance Responses to Evil, Positive (Neutral and Good), Familiar, and Unfamiliar Faces at 17- and 220-msec Exposure Durations

\begin{tabular}{|c|c|c|c|c|c|c|}
\hline \multirow[b]{2}{*}{ Faces } & \multicolumn{3}{|c|}{ Probability of Response } & \multicolumn{3}{|c|}{$\begin{array}{c}\text { Range-Adjusted } \\
\text { Response Amplitude }\end{array}$} \\
\hline & $M$ & $S D$ & $n$ & $M$ & $S D$ & $n$ \\
\hline \multicolumn{7}{|c|}{ 220-msec Duration } \\
\hline Evil & .60 & .34 & 37 & .45 & .21 & 23 \\
\hline Positive & .56 & .31 & 37 & .36 & .14 & 23 \\
\hline Familiar & .57 & .30 & 37 & .39 & .11 & 20 \\
\hline Unfamiliar & .47 & .35 & 37 & .29 & .15 & 20 \\
\hline \multicolumn{7}{|c|}{ 17-msec Duration } \\
\hline Evil & .45 & .36 & 37 & .23 & .15 & 14 \\
\hline Positive & .48 & .33 & 37 & .32 & .14 & 14 \\
\hline Familiar & .47 & .32 & 37 & .24 & .12 & 20 \\
\hline$\underline{\text { Unfamiliar }}$ & .47 & .33 & 37 & .29 & .20 & 20 \\
\hline
\end{tabular}


faces. The interaction term was significant for Rara in both the participants and items analyses $\left[F_{\mathrm{p}}(1,19)=11.18\right.$, $\left.p<.005 ; F_{\mathrm{i}}(1,22)=5.71, p<.05\right]$. For Prob, the interaction was significant by items and close to significance by participants $\left[F_{\mathrm{p}}(1,36)=3.47, p=.07 ; F_{\mathrm{i}}(1,22)=4.90\right.$, $p<.05]$. Responses to familiar faces were more likely and were larger than responses to unfamiliar faces at $220 \mathrm{msec}$ [Rara, $t_{\mathrm{p}}(19)=3.22, p<.005$, and $t_{\mathrm{i}}(22)=3.26, p<$ $.005 ;$ Prob, $t_{\mathrm{p}}(36)=2.62, p<.01$, and $t_{\mathrm{i}}(22)=2.37, p<$ $.05]$ but not at $17 \mathrm{msec}$ [Rara, $t_{\mathrm{p}}(19)=1.35$, n.s., and $t_{\mathrm{i}}(22)=0.02$, n.s.; Prob, $t_{\mathrm{p}}(36)=0.02$, n.s., and $t_{\mathrm{i}}(22)=$ 0.17 , n.s.]. Responses were more likely and larger at $220 \mathrm{msec}$ than at $17 \mathrm{msec}$ for familiar faces [Rara, $t_{\mathrm{p}}(19)=4.37, p<.005$, and $t_{\mathrm{i}}(22)=5.13, p<.005$; Prob, $t_{\mathrm{p}}(36)=2.50, p<.01$, and $t_{\mathrm{i}}(22)=4.31, p<.005$ ], but there was no difference between 220 and $17 \mathrm{msec}$ for unfamiliar faces (all $t \mathrm{~s}<1$ ). Figure 1 illustrates the interaction between the effects of exposure duration and face familiarity.

Specific contrasts had been planned among the evil, neutral, and good faces. For the participants analysis, evil, neutral, and good faces were defined according to each participant's own ratings. A face was defined as evil for a particular participant if the rating was less than zero, as neutral if the rating was zero or one, and as good if the rating was two or three. Data for the Rara variable were examined from the participants who yielded at least two valid responses for each face type. This method resulted in small numbers of participants (13 at $220 \mathrm{msec}$ and 6 at $17 \mathrm{msec}$ ) with sufficient valid responses for the Rara analysis. Consequently, the face types neutral and good were collapsed into one category of positive faces. This yielded a sample size of $n=23$ at $200 \mathrm{msec}$ and $n=14$ at $17 \mathrm{msec}$. For the items analysis, faces were categorized as evil, neutral, or good according to their intended category, and the neutral and good faces were collapsed into one category of positive faces for consistency with the participants analysis. The Prob variable was treated similarly to the Rara variable for consistency.

The specific planned contrasts of evil and positive faces were investigated by using the polynomial difference method for the participants analysis and the linear contrasts method for the items analysis. The only significant result was the comparison of positive and evil faces on Rara in the $17-\mathrm{msec}$ condition $\left[F_{\mathrm{p}}(1,13)=5.27, p<.04\right.$, $\left.t_{\mathrm{i}}(21)=2.43, p<.03\right]$, with positive faces ( mean $=0.32$, $S D=0.14)$ yielding larger SCRs than evil faces did (mean $=0.23, S D=0.15$ ). At the 220-msec exposure, the comparison of positive and evil faces on Rara showed the opposite trend, but the contrast was not significant (positive, mean $=0.36, S D=0.14$; evil, mean $=0.45$, $S D=0.21)$.

In summary, SCR does not distinguish familiar from unfamiliar faces in the absence of awareness. However, there is a suggestion that there may be a differential SCR to positive and evil faces of which the participant is unaware, with positive faces yielding higher SCR than evil faces do. One possible explanation for this effect being observed at an exposure of $17 \mathrm{msec}$ but not $220 \mathrm{msec}$ has been offered by Mogg and Bradley (1999). They note that visible or near visible stimuli may result in increased conscious efforts to process the stimuli (in the present Experiment 1 , perhaps participants were attempting to retrieve the celebrity's name), and this might have interfered
A

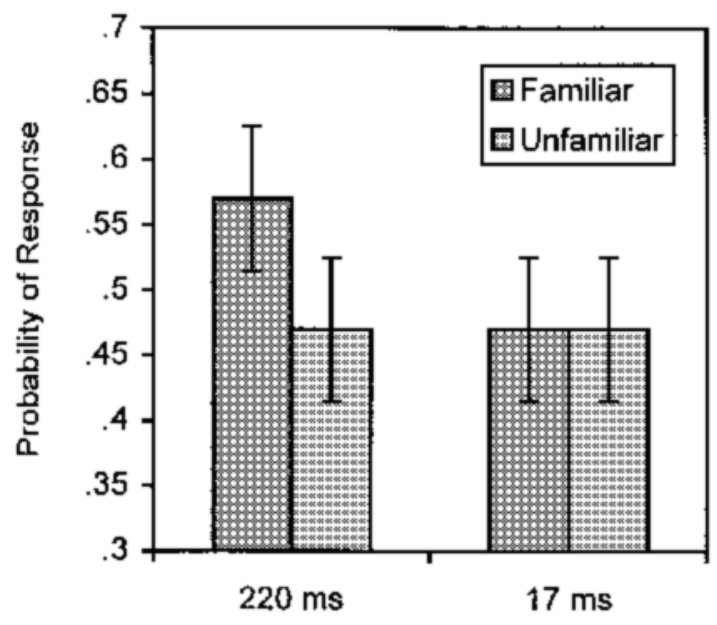

Exposure duration

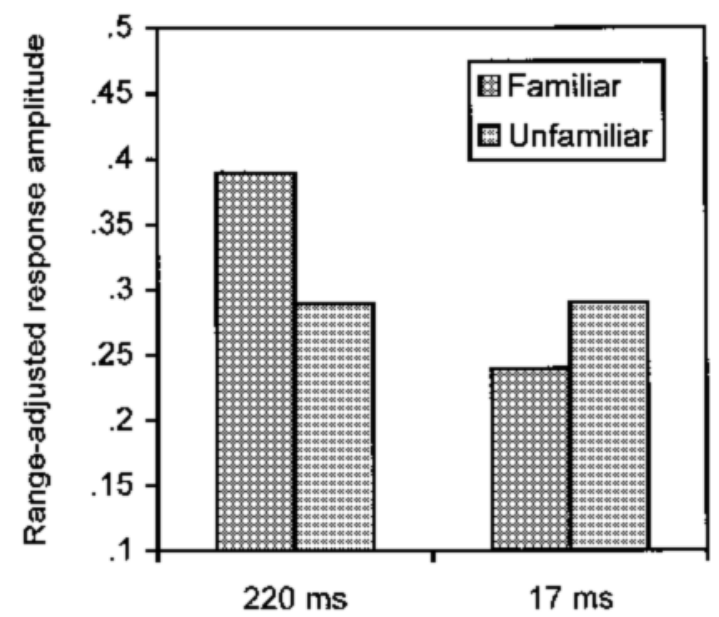

Exposure duration

Figure 1. Interaction between exposure duration and face familiarity, based on participants data for the variables probability of response in panel $A$ and range-adjusted response amplitude in panel $B$. The error bars represent within-participants $95 \%$ confidence intervals, calculated according to Equation 4 in Loftus and Masson (1994, p. 485). 
with the response of the autonomic system that resulted from unconscious processing. The SCRs might have been affected by this effortful cognitive processing rather than by an automatic response to the stimulus valence.

\section{EXPERIMENT 2}

Using a much stricter criterion for awareness than that used in previous research, in Experiment 1 we failed to find any evidence of a differential SCR to familiar and unfamiliar faces. In Experiment 2, a behavioral dependent variable, associative priming, rather than a physiological measure was used to explore further the possibility of familiar face processing below the threshold of awareness. Associative priming describes the effect whereby a familiarity decision to the face of a celebrity is speeded by the prior presentation of the face of a close associate (e.g., Hillary and Bill Clinton) in comparison with the prior presentation of a nonassociated celebrity face. Bruce and Valentine (1986) demonstrated associative priming with prime face exposure duration of $250 \mathrm{msec}$ and stimulus onset asynchrony (SOA) of $250 \mathrm{msec}$. In Experiment 2, associative priming was compared between prime faces presented for $17 \mathrm{msec}$ and for $220 \mathrm{msec}$.

\section{Method}

Participants. A total of 80 participants were recruited from among staff and students at Goldsmiths College. Data from 6 participants were omitted from the analysis: 5 of these participants generated more than $50 \%$ incorrect responses to familiar faces, and 1 selected the response key incorrectly. Data were analyzed from 37 participants in the $17-\mathrm{msec}$ priming condition (mean age $=32.9, S D=14.0$ ) and 37 participants in the 220 - $\mathrm{msec}$ priming condition (mean age $=$ $31.3, S D=9.1$ ).

Stimuli. Twenty pairs of closely associated celebrities whose faces were expected to be familiar to the general population were selected (listed in Appendix B). Photographs were scanned to produce images in the same format as described for Experiment 1. A further 20 unfamiliar faces not used in Experiment 1 were also selected.

Apparatus. A personal computer running MEL2 software with a screen resolution of $640 \times 480$ was used to display the faces. Reaction time and response selection was logged by the computer.

Design. A mixed design was employed, with prime face exposure duration ( $220 \mathrm{vs.} 17 \mathrm{msec})$ as a between-participants factor and prime type (related vs. unrelated) as a within-participants factor. There were two prime types: related, with 10 familiar targets preceded by related primes (e.g., Jerry Hall and Mick Jagger); and unrelated, with 10 familiar targets preceded by unrelated primes (e.g., Hillary Clinton and Prince Charles). The familiar target faces were counterbalanced across prime types so that each familiar target face was preceded by a related prime face for half the participants, and by an unrelated prime face for the remainder. Primes in the unrelated condition served as primes in the related condition for a different target face and for different participants in such a way that each participant saw each prime only once followed by a familiar target face. There were also 20 unfamiliar targets preceded by a famous prime face. The same 20 familiar primes served as primes for familiar and unfamiliar faces, so each prime occurred twice, once before a familiar face and once before an unfamiliar face. Only responses to familiar targets were relevant to the experimental hypothesis.

Procedure. The participants were asked to make speeded familiarity decisions in response to a series of familiar and unfamiliar target faces displayed on a computer screen one after the other. Half the targets were familiar and half were unfamiliar. A mask com- prising jumbled face parts was presented in the center of the screen for $500 \mathrm{msec}$, the prime face was then displayed for either 17 or $220 \mathrm{msec}$, the pattern mask was presented again for $500 \mathrm{msec}$, and finally the target face was presented until the participant entered a valid response on the keyboard. The SOA was either 517 or 720 msec.

The participants were instructed that they would see a series of familiar and unfamiliar faces on the screen and were to respond by pressing keys labeled $\mathrm{Y}$ or $\mathrm{N}$ to indicate whether or not the face was recognized. They were asked to respond as quickly and accurately as possible. They were informed that before each target face was displayed another face would be displayed for either 17 or $220 \mathrm{msec}$, preceded and followed by a mask composed of a random assortment of facial features. In the 17-msec condition, participants were informed that it was unlikely that they would recognize any of these faces but that they should attend carefully to the screen. Two practice trials with one familiar and one unfamiliar target face preceded the experimental trials.

\section{Results and Discussion}

The reaction time data were examined, and responses with a $z$ score of more than 2.5 , or responses less than $200 \mathrm{msec}$, were omitted as outliers. No participant reported recognizing any of the prime faces in the 17-msec priming condition. One target face, which generated an incorrect response from more than half of the participants, was omitted from the analysis. The data are shown in Table 2.

The data were analyzed by two-factor ANOVA with one within-participants and items factors of prime type (related vs. unrelated) and one between-participants but within-items factor of prime exposure duration (17 vs. $220 \mathrm{msec}$ ).

The main effects of prime type $\left[F_{\mathrm{p}}(1,72)=2.79\right.$, n.s.; $F_{\mathrm{i}}(1,18)=1.98$, n.s.] and prime exposure duration (both $\left.F_{\mathrm{S}}<1\right)$ were not significant, but the interaction was significant for participants and items $\left[F_{\mathrm{p}}(1,72)=4.11, p<\right.$ $\left..05 ; F_{\mathrm{i}}(1,18)=5.34, p<.05\right]$. Reaction times to recognize target faces were faster following a related prime than following an unrelated prime at the 220 -msec prime exposure $\left[t_{\mathrm{p}}(36)=3.29, p<.005 ; t_{\mathrm{i}}(18)=2.14, p<\right.$ $.05]$, but there was no facilitation from related primes presented for $17 \mathrm{msec}\left[t_{\mathrm{p}}\right.$ and $\left.t_{\mathrm{i}}<1\right]$.

The two experimental conditions differed in both prime exposure duration (17 vs. $220 \mathrm{msec}$ ) and primetarget SOA (517 vs. $720 \mathrm{msec}$ ). It could be argued that $17 \mathrm{msec}$ is a sufficient duration for associative priming to occur but that the SOA is too short for the facilitation to be detected. However, Bruce and Valentine (1986) observed associative priming of a face familiarity decision from prime faces presented for $250 \mathrm{msec}$ with SOAs set at 250,500 , and $750 \mathrm{msec}$. Therefore, the SOA for both

Table 2

Mean Reaction Time (Milliseconds) for Related and Unrelated Prime Type and for 17-msec and 220-msec Prime Exposure Durations

\begin{tabular}{|c|c|c|c|c|c|c|c|}
\hline \multicolumn{4}{|c|}{$220 \mathrm{msec}$} & \multicolumn{4}{|c|}{$17 \mathrm{msec}$} \\
\hline \multicolumn{2}{|c|}{ Related } & \multicolumn{2}{|c|}{ Unrelated } & \multicolumn{2}{|c|}{ Related } & \multicolumn{2}{|c|}{ Unrelated } \\
\hline$M$ & $S D$ & $M$ & $S D$ & $M$ & $S D$ & $M$ & $S D$ \\
\hline 879 & 227 & 944 & 245 & 907 & 223 & 900 & 193 \\
\hline
\end{tabular}


conditions of Experiment 2 lie within the range for which associative priming is known to occur. This does depend on there not being an interaction of exposure duration and SOA; such an interaction is considered unlikely.

This result suggests that a $17-\mathrm{msec}$ prime exposure, in the absence of awareness, generates insufficient activation of identity-specific semantic information to support associative priming.

\section{EXPERIMENT 3}

In Experiment 1, participants responded differently to faces of good and evil celebrities on a measure of SCR, without conscious awareness of the facial identities. This raised the possibility that participants might be able to discriminate the valence of a celebrity face with better than chance accuracy in a direct test. Using the same stimuli and presentation conditions as in Experiment 1-that is, 17-msec exposure with forward and backward masking to render the faces consciously undetectable-we simply asked participants to decide whether each face belonged to a good or an evil celebrity. We reasoned that when faces were unconsciously recognized, the participants would be able to select the correct response with better than chance accuracy, either by detecting their emotional reaction to the face or from the influence of some entirely unconscious process.

\section{Method}

Participants. A total of 29 participants were recruited from among staff and students at Goldsmiths College. Data from 6 participants were omitted from the analysis: 4 failed to correctly identify a minimum of $50 \%$ of the celebrity faces, and 2 responded incorrectly by attempting to categorize the backward mask as good or evil. Data were analyzed from the remaining 23 participants, whose ages ranged from 21 to 37 (mean $=26.9, S D=3.9$ ).

Stimuli. The celebrity faces from Experiment 1 were used again.

Apparatus. A personal computer running MEL2 software with a screen resolution of $640 \times 480$ was used to display the faces. Response selection was logged by the computer.

Design. A within-participants design was employed with a single factor of valence, good versus evil, categorized by the participants' own ratings.

Procedure. Participants were asked to make a two-alternative forced-choice decision on the valence of celebrity faces presented for $17 \mathrm{msec}$ and both forward and backward masked. The faces were presented one at a time centrally on the screen in a different random sequence for each participant. A mask comprising jumbled face parts was presented in the center of the screen for $500 \mathrm{msec}$, the celebrity face was then displayed for $17 \mathrm{msec}$, the pattern mask was presented again for $500 \mathrm{msec}$, and finally the text "good or evil?" was presented until the participant entered a valid response on the keyboard. The participants were asked to guess if they were unable to see the face. They were not asked to respond as quickly as possible. The response keys were counterbalanced so that approximately half the participants pressed with their left hand for $G$ and right hand for E, and the other half had the reverse responses. Six buffer faces preceded the 18 celebrity faces. After completing the task, the participants were asked whether they had been able to detect the identity of any face. They were encouraged to guess identities if they were unsure. Any faces correctly identified were omitted from the analysis of results.
Following this task, the participants were again presented with the faces one at a time in a random sequence and were asked to identify each face, by name or description, and give their personal opinion of the valence of the celebrity. Each face was displayed until the participant initiated presentation of the next face. The rating scale was the same as that used in Experiment 1.

\section{Results and Discussion}

Responses to faces that were recognized from 17-msec presentation and to faces that were not subsequently correctly identified were omitted from the analysis, leaving a total of 332 valid responses. Overall, $62.7 \%$ of the faces were rated as zero or positive and were classified as good faces, and the remaining $37.3 \%$ were rated negatively and classified as evil. The overall proportion of "good" responses was $54.2 \%$, and the proportion of "evil" responses was $45.8 \%$. The probability of a correct response's being made at random can be calculated according to the following equation, which yields an expected chance accuracy rate of $51.1 \%$.

$$
\begin{aligned}
P(\text { good face }) \times & P(\text { good response }) \\
& +P(\text { evil face }) \times \mathrm{P}(\text { evil response }) .
\end{aligned}
$$

The proportion of correct responses was calculated for each participant and separately for each item, and the data were compared against the chance level in a onesample $t$ test. For participants, the overall mean proportion of correct responses was $0.579(S D=0.13)$, and for items, the overall mean proportion was $0.584(S D=0.14)$. Correct responses were selected significantly more often than chance would predict $\left[t_{\mathrm{p}}(22)=2.55, p<.02\right.$, onetailed, and $t_{\mathrm{i}}(17)=2.23, p<.02$, one-tailed]. An alternative method of analysis is the chi-square test to compare the expected and actual frequencies of responses in a $2 \times$ 2 table formed by the combinations of face valence (evil vs. good) and selected response (evil vs. good) over all participants and items. This also yielded a significant result $\left[\chi^{2}(1)=5.43, p<.02\right.$, two-tailed $]$.

The conclusion can be drawn that participants were able to discriminate the affective valence of a celebrity face with better than chance accuracy in the absence of conscious awareness.

\section{GENERAL DISCUSSION}

SCRs were larger and more probable to familiar than to unfamiliar faces at the 220-msec exposure, replicating the effect found by Tranel and Damasio (1985) and Ellis et al. (1993). However there was no evidence of differential SCR to familiar versus unfamiliar faces at the 17msec exposure. The associative priming task yielded evidence of a priming effect with prime exposure duration of $220 \mathrm{msec}$ but not $17 \mathrm{msec}$. Thus there was no evidence of associative priming without awareness of the prime.

Given that in this study we found some recognition at $17 \mathrm{msec}$, and that a pilot study yielded substantial recognition at $50 \mathrm{msec}$, it appears likely that the exposure du- 
rations used by Ellis et al. (1993) and Morrison et al. (2000) were sufficient to allow awareness. A postexperiment check on awareness is a necessary precaution. We recognize that the awareness check in the present experiments may have lacked sensitivity and that it would have been preferable in principle to have questioned participants after each stimulus presentation (although impossible in practice without interfering with SCR recording). However, the observation that SCR indicated discrimination of familiar from unfamiliar faces at $220 \mathrm{msec}$ and failed to do so at $17 \mathrm{msec}$ suggests no or very little undetected awareness.

Our results suggest that the participants did not discriminate familiar from unfamiliar faces or show evidence of associative priming when the faces were presented too briefly for awareness.

The Burton et al. (1991) model proposes that prosopagnosia results from a partial disconnection of face processing system from the person recognition system. The dual-route models (Bauer, 1984; Breen et al., 2000; Tranel et al., 1995) suggest that prosopagnosia is due to damage to a neural pathway responsible for conscious recognition. In the present experiments, conscious recognition in neurologically intact individuals was prevented by brief presentation. However, we found no evidence of covert recognition of face familiarity or associative priming. Thus, the data suggest that very brief presentation does not provide an adequate model of the types of covert recognition reported in prosopagnosia, although it remains possible that there may be an exposure duration above $17 \mathrm{msec}$ that will permit familiarity detection without conscious awareness.

Experiment 1 provided evidence that SCRs to $17-\mathrm{msec}$ presentations were significantly larger to positive faces than to evil faces. Although this result should be treated with caution in view of the small sample size $(n=14)$, Experiment $3(n=23)$ yielded behavioral evidence of discrimination of good from evil faces in the absence of conscious awareness. In order to produce differential responses to evil and positive faces in the absence of differential responses to familiar and unfamiliar faces, it would need to be the case that the valence of a stimulus was activated and able to influence participants' responses when the stimulus familiarity was not. From an evolutionary perspective, it seems plausible that the adaptive function of face recognition arises from establishing the "friend or foe" status of an individual; therefore, affective valence may have played an important role in the evolution of our face recognition skills.

The finding of differential SCR to the faces of evil and positive celebrities without awareness is also consistent with the research of Ohman, Dimberg, Esteves, and colleagues (reviewed in Ohman et al., 1995, and Dimberg, Thunberg, \& Elmehed, 2000). These authors have consistently reported differential SCR to positive and negative facial emotional expressions presented without awareness.

It is interesting to note that good faces yielded larger SCRs than did evil faces. We had predicted the opposite effect, in line with the effects reported by Ohman et al. (1995). This result is in need of replication and extension and so warrants further research.

The present study raises the possibility of a confound in previous work. Experiments demonstrating higher SCRs to familiar than to unfamiliar faces in prosopagnosia (e.g., Tranel \& Damasio, 1985; Tranel et al., 1995) have used as their familiar stimuli celebrities who are likely to have been regarded, on the average, positively rather than negatively. Hence the familiarity of the famous faces was confounded with their positive affective valence. If the result of the present study showing higher SCR to positive faces proves replicable, which of these factors was responsible for the differential responding will become an empirical question. Replication with faces of celebrities regarded by the participant as evil would clarify this question.

In conclusion, we found no evidence of covert face familiarity recognition or associative priming in neurologically intact participants under strict conditions designed to prevent awareness. Claims of discrimination of familiar from unfamiliar faces and associative priming of famous faces in circumstances in which a neurologically intact participant is unaware of the presented faces need to be established under more carefully controlled conditions. A check on the awareness of stimuli is required before claims of covert recognition can be substantiated.

\section{REFERENCES}

BAUER, R. M. (1984). Autonomic recognition of names and faces in prosopagnosia: A neuropsychological application of the guilty knowledge test. Neuropsychologia, 22, 457-469.

BAUER, R. M. (1986). The cognitive neuropsychology of prosopagnosia. In H. D. Ellis, M. A. Jeeves, F. Newcombe, \& A. Young (Eds.), Aspects offace processing (pp 253-267). Dordrecht: Martinus Nijhoff.

BAUER, R. M., \& VERFAellie, M. (1988). Electrodermal discrimination of familiar but not unfamiliar faces in prosopagnosia. Brain \& Cognition, 8, 240-252.

Breen, N., Caine, D., \& Coltheart, M. (2000). Models of face recognition and delusional misidentification: A critical review. Cognitive Neuropsychology, 17, 55-71.

Bruce, V., \& VAlentine, T. (1986). Semantic priming of familiar faces. Quarterly Journal of Experimental Psychology, 38A, 125-150.

Burton, A. M., Young, A. W., Bruce, V., Johnston, R. A., \& Ellis, A. W. (1991). Understanding covert recognition. Cognition, 39, 129-166.

De Haan, E. H. F., Bauer, R. M., \& Greve, K. W. (1992). Behavioural and physiological evidence for covert face recognition in a prosopagnosic patient. Cortex, 28, 77-95.

Dimberg, U., Thunberg, M., \& Elmehed, K. (2000). Unconscious facial reactions to emotional facial expressions. Psychological Science, 11, 86-89.

Ellis, H. D., \& Young, A. W. (1990). Accounting for delusional misidentifications. British Journal of Psychiatry, 157, 239-248.

Ellis, H. D., Young, A. W., \& Koenken, G. (1993). Covert face recognition without prosopagnosia. Behavioural Neurology, 6, 27-32.

Ellis, H. D., Young, A. W., Quayle, A. H., \& De Pauw, K. W. (1997). Reduced autonomic responses to faces in Capgras delusion. Proceedings of the Royal Society of London: Series B, 264, 1085-1092.

LofTus, G. R., \& Masson, M. E. J. (1994). Using confidence intervals in within-subject designs. Psychonomic Bulletin \& Review, 1, 476-490.

Maltzman, I., \& Boyd, G. (1984). Stimulus significance and bilateral SCRs to potentially phobic pictures. Journal of Abnormal Psychology, 93, 41-46.

Martin, I., \& Venables, P. H. (1980). Techniques in psychophysiology. New York: Wiley. 
MeEREs, S. L., \& GraVes, R. E. (1990). Localization of unseen visual stimuli by humans with normal vision. Neuropsychologia, 28, 1231-1237.

MogG, K., \& Bradley, B. P. (1999). Orienting of attention to threatening facial expressions presented under conditions of restricted awareness. Cognition \& Emotion, 13, 713-740.

Moore, V., \& Valentine, T. (1998). The effect of age of acquisition on speed and accuracy of naming famous faces. Quarterly Journal of Experimental Psychology, 51A, 485-513.

Moore, V., Valentine, T. \& Turner, J. (1999). Age of acquisition and cumulative frequency have independent effects. Cognition, 72, 305-309.

Morrison, D. J., Bruce, V., \& Burton, A. M. (2000). Covert face recognition in neurologically intact participants. Psychological Research, 63, 83-94.

Ohman, A., Esteves, F., \& Soares, J. F. (1995). Preparedness and preattentive associative learning: Electrodermal conditioning to masked stimuli. Journal of Psychophysiology, 9, 99-108.
Ohman, A., \& Soares, J. J. F. (1994). "Unconscious anxiety”: Phobic responses to masked stimuli. Journal of Abnormal Psychology, 103, 231-240.

Tranel, D., \& Damasio, A. R. (1985). Knowledge without awareness: An autonomic index of facial expression by prosopagnosics. Science, 228, 1453-1454.

Tranel, D., Damasio, H. \& Damasio, A. R. (1995). Double dissociation between overt and covert recognition. Journal of Cognitive Neuroscience, 7, 425-432.

Young, A. W. (1998). Face and mind. Oxford: Oxford University Press.

Young, A. W., Hellawell, D., \& De Haan, E. H. F. (1988). Crossdomain semantic priming in normal subjects and a prosopagnosic patient. Quarterly Journal of Experimental Psychology, 40A, 561580 .

ZaJonc, R. B. (1980). Feeling and thinking: Preferences need no inferences. American Psychologist, 35, 151-175.

APPENDIX A

Stimuli Used in Experiment 1

\begin{tabular}{lll}
\hline \multicolumn{1}{c}{ Evil Celebrities } & \multicolumn{1}{c}{ Good Celebrities } & \multicolumn{1}{c}{ Neutral Celebrities* } \\
\hline Myra Hindley (murderess) & Clive Anderson (TV presenter) & Craig Charles (TV actor) \\
Adolf Hitler & David Bellamy (TV botanist) & Paul Daniels (TV magician) \\
Saddam Hussein & Roy Castle (children's TV ) & Chris Evans (TV, radio) \\
Richard Nixon & Lenny Henry (comedian) & Mikhail Gorbachev \\
OJ Simpson & Nelson Mandela & Danny-John Jules (TV actor) \\
Mike Tyson & Claire Rayner (agony aunt) & JF Kennedy \\
\hline
\end{tabular}

*Plus 12 unfamiliar faces.

\section{APPENDIX B}

Stimuli Used in Experiment 2

\begin{tabular}{lll}
\hline \multicolumn{1}{c}{ Prime } & \multicolumn{1}{c}{ Target } & \multicolumn{1}{c}{ Comment } \\
\hline Cherie Blair & Tony Blair & U.K. prime minister and wife \\
Hillary Clinton & Bill Clinton & USA president and wife \\
Princess Diana & Prince Charles & U.K. royal family \\
Sarah Ferguson & Prince Andrew & U.K. royal family \\
Sophie Rhys-Jones & Prince Edward & U.K. royal family \\
Nicole Kidman & Tom Cruise & Media celebrity couple \\
Jerry Hall & Mick Jagger & Media celebrity couple \\
Liz Hurley & Hugh Grant & Media celebrity couple \\
Oliver Hardy & Stan Laurel & Comedy duo \\
Hale & Pace & Comedy duo \\
Jennifer Saunders & Dawn French & Comedy duo \\
Ronnie Barker & Ronnie Corbett & Comedy duo \\
Eric Morcomb & Ernie Wise & Comedy duo \\
Judy Finnegan & Richard Madeley & "Richard and Judy" TV presenters \\
Dominic Brunt & Lisa Riley & Soap opera couple: Emmerdale Farm \\
William Tarmey & Elizabeth Dawn & Soap opera couple: Coronation Street \\
Sid Owen & Patsy Palmer & Soap opera couple: EastEnders \\
Gillian Anderson & David Duchovny & Fictional couple: The X Files \\
Neil Morrissey & Martin Clunes & Sitcom friends: Men Behaving Badly \\
Sharon & Tracy & Sitcom sisters: Birds of a Feather \\
\hline
\end{tabular}

(Manuscript received March 19, 2001;

revision accepted for publication May 22, 2001.) 